\title{
СТОМАТОЛОГИЯ
}

УДК 61:616:616-01

Ермолаева Л.А. ${ }^{1}$, Севбитов А.В. ${ }^{2}$, Пеньковой Е. А. ${ }^{1}$,

Шишкин А.Н. ${ }^{1}$ Шевелева Н. А. ${ }^{1}$, Шевелева М.A. ${ }^{1}$,

Соколович Н. A. ${ }^{1}$, Михайлова Е. С. ${ }^{1}$ Хабарова O.B. ${ }^{1}$

ЭТИОПАТОГЕНЕТИЧЕСКИЕ МЕХАНИЗМЫ

РАЗВИТИЯ ВОСПАЛИТЕЛЬНЫХ ЗАБОЛЕВАНИЙ ПАРОДОНТА У БОЛЬНЫХ С ОЖИРЕНИЕМ

${ }^{1}$ Санкт-Петербургский государственный университет, Российская Федерация, 199034, Санкт-Петербург, Университетская наб., 7-9

${ }^{2}$ Первый Московский государственный медицинский университет им. И. М.Сеченова, Российская Федерация, 119991, Москва, ул. Трубецкая, 8, стр. 2

В статье изложены современные научные данные об этиопатогенезе и взаимосвязи ожирения и воспалительных заболеваний пародонта, которые представляют серьезную медико-социальную проблему во всем мире. Представлены результаты оригинального исследования по данной проблеме, а также рассмотрены перспективы ее дальнейшего изучения. В проведенном исследовании участвовало 153 пациента (из них 102 больных с ожирением) и использовались такие методы, как клиническое и рентгенологическое исследование состояния тканей пародонта, оценка состояния микроциркуляторного сосудистого русла тканей пародонта и костной ткани челюстных костей с использованием методов ультразвуковой допплерографии и ультразвуковой денситометрии. В ходе сравнения степени тяжести патологии пародиста в основной и контрольной группах при помощи корреляционного анализа были получены достоверные различия между группами $(p<0,0001)$. Полученные в результате допплерографии сосудов пародонта данные продемонстрировали обратную корреляционную связь между показателями индекса массы тела и линейной систолической скоростью кровотока $(r=-0,6754, p<0,001)$. Также при оценке показателей денситометрии была получена обратная корреляционная связь между показателями индекса массы тела и плотностью костной ткани $(r=-0,61, p<0,001)$. В результате анализа полученных данных были сделаны выводы о том, что существует этиопатогенетическая взаимосвязь между заболеваниями пародонта и ожирением. Понимание особенностей взаимовлияния этих двух заболеваний облегчит оценку прогноза у таких пациентов, упростит выбор необходимой терапии с учетом влияния на микроциркуляцию и минеральную плотность костной ткани. Библиогр. 40 назв. Ил. 2.

Ключевые слова: пародонтит, ожирение, С-реактивный белок, лептин, дислипидемия, ультразвуковая денситометрия, допплерография сосудов пародонта.

(c) Санкт-Петербургский государственный университет, 2017 


\section{ETIOPATHOGENETIC MECHANISMS OF DEVELOPMENT OF INFLAMMATORY PERIODONTAL DISEASES IN PATIENTS WITH OBESITY}

Ermolaeva L. A. ${ }^{1}$, Sevbitov A. V. ${ }^{2}$, Penkovoi E. A. ${ }^{1}$, Shishkin A. N. ${ }^{1}$, Sheveleva N.A. ${ }^{1}$, Sheveleva M. $A^{1}$., Sokolovich N. A. ${ }^{1}$, Mikhaylova E. S. ${ }^{1}$, Khabarova O. V. ${ }^{1}$

${ }^{1}$ St. Petersburg State University, 7-9, Universitetskaya nab., St. Petersburg, 199034, Russian Federation

2 I. M. Sechenov First Moscow State Medical University, 8, str. 2, Trubetskaya ul., Moscow, 119991, Russian Federation

The article presents modern scientific data on etiopathogenesis and the relationship between obesity and inflammatory periodontal diseases, which represent a serious medical and social problem throughout the world. The results of the original research on this problem are presented, as well as the prospects for its further study. 153 patients (102 of them with obesity) participated in the study and used such methods as clinical and radiological examination of the condition of periodontal tissues, evaluation of the microcirculatory vascular bed of periodontal tissues and bone tissue of the jaw bones using the methods of ultrasonic dopplerography and ultrasonic densitometry. Comparing the severity of parodist pathology in the main and control groups by means of correlation analysis, significant differences between groups were obtained $(p<0.0001)$. Data obtained as a result of dopplerography of periodontal vessels showed an inverse correlation between the indices of the body mass index and the linear systolic blood flow velocity $(r=-0.6754, p<0.001)$. Also, in the evaluation of densitometry, an inverse correlation was obtained between the indices of the body mass index and the density of bone tissue $(r=-0.61, p<0.001)$. As a result of the analysis of the data obtained, it was concluded that there is an etiopathogenetic relationship between periodontal diseases and obesity. Understanding the peculiarities of the interference of these two diseases will facilitate the estimation of the prognosis in such patients, simplifying the choice of necessary therapy taking into account the effect on microcirculation and bone mineral density. Refs 40. Figs 2 .

Keywords: periodontitis, obesity, C-reactive protein, leptin, dislipidemia, ultrasonic densitometry, dopplerography of periodontal vessels.

\section{Введение}

Данные современных эпидемиологических исследований демонстрируют тенденцию к увеличению числа пародонтологических заболеваний среди населения нашей страны [1]. Повышение частоты возникновения патологии пародонта приходится на возраст 33-48 лет и к 45 годам достигает $98 \%$. Даже среди молодежи 16-20 лет заболеваемость пародонта возрастает и встречается в 55-89\% [2].

Возникновению заболеваний пародонта сопутствуют многие факторы: как местные, так и общие, способные инициировать и провоцировать воспалительные процессы в пародонте. Среди заболеваний тканей пародонта первое место принадлежит хроническому генерализованному пародонтиту.

На заседании президиума секции пародонтологии Стоматологической ассоциации России в 2001 году была принята классификация заболеваний пародонта, в соответствии с которой пародонтит - это воспалительное заболевание тканей пародонта, сопровождающееся деструкцией связочного аппарата периодонта и альвеолярной кости [3].

Многими исследованиями было доказано, что ведущую роль в развитии воспалительных процессов в тканях пародонта играют микроорганизмы, содержащиеся в зубной бляшке, в особенности штаммы пародонтопатогенных анаэробных микроорганизмов [4]. Микроорганизмы и продукты их жизнедеятельности, состоящие из эндотоксинов, экзоэнзимов и антигенного материала, вызывают нарушения местных механизмов защиты тканей пародонта и дисбаланс микрофлоры [5]. Также в развитии патологических процессов в тканях пародонта немалую роль 
играют местные травмирующие факторы, такие как нарушение окклюзии, наличие кариозных полостей, неудовлетворительная гигиена полости рта, парафункции жевательных мышц, бруксизм, дефекты пломб и протезов и др. [6].

Активизация микрофлоры начинается при снижении местного иммунного ответа организма и наличии экологической ниши. Следствием является активация воспалительных процессов в тканях пародонта [7].

В ходе некоторых исследований была определена степень ассоциации патогенных бактерий с возникновением воспалительных заболеваний тканей пародиста [8]. В ходе многочисленных исследований микроорганизмов, обитающих в пародонтальных карманах, были определены наиболее патогенные штаммы [9; 10]. В этих исследованиях использовались фазовая темнопольная и контрастная микроскопия, иммунодиагностические, ферментативные и молекулярные методы, бактериальное культивирование. В результате были определены микроорганизмы, непосредственно связанные с возникновением хронического генерализованного пародонтита: Bacteroides forsythus, Porphyromonas gingivalis, Actinobacillus actinomycetemcomitans [9].

Состояние здоровья человека во многом определяется его микрофлорой. В полости рта и глотке человека встречается более 300 видов микробов. Микрофлора полости рта подразделяется на облигатную и факультативную (транзиторную) [11]. Важным фактором возникновения и поддержания воспалительного процесса в ротовой полости, да и в организме в целом является дисбиоз. Дисбиоз - это микроэкологические нарушения, которые выражаются в нарушениях состава и функций нормальной микрофлоры. Именно поэтому современные стоматологи уделяют такое внимание проблеме дисбиоза и дисбактериоза полости рта [12].

\section{С-реактивный белок как маркер воспалительных явлений в пародонте}

Как известно, пародонтит - это воспалительное заболевание опорных тканей зубов, вызываемое определенными группами микроорганизмов, результатом которого является прогрессирующая деструкция тканей пародонта с образованием зубодесневого кармана. Это состояние возникает в ответ на присутствие граммотрицательной бактериальной инфекции, находящейся в зубных отложениях [10]. Болезнь, как правило, протекает бессимптомно годами и может быть обнаружена при клиническом осмотре или после рентгенологической диагностики. Относительно недавно исследователи начали выделять местный и системный воспалительные процессы, которые вызывают патологическую реакцию на инициальную комменсальную микрофлору [13]. Было отмечено повышение уровня С-реактивного белка (СРБ) при гингивите и пародонтите [14].

СРБ - это реагент острой фазы, производимый в печени в ответ на различные воспалительные стимулы. Последние исследования показали, что его уровень повышается при заболеваниях пародиста [15]. Тем не менее не все исследования выявили связь между деструктивными заболеваниями пародонта и СРБ [16]. Эти результаты могут быть связаны с различными степенями тяжести деструкции пародонта или со степенью заболевания в различных исследованиях.

Отмечено, что после консервативного лечения пародонтита снижались уровень СРБ в десневой жидкости и уровни биомаркеров, специфичных к трем 
основным аспектам пародонтита (степень воспалительной реакции, степень деградации коллагеновых волокон и костной ткани) [17]. Также эти показатели коррелируют с клиническими признаками заболевания пародонта [18].

\section{Взаимовлияние заболеваний пародонта и общесоматических заболеваний}

В подавляющем большинстве публикаций на данную тему доказана прямая зависимость между микроорганизмами зубного налета и воспалением в пародонте [19]. Однако присутствие патогенных микроорганизмов не объясняет различия в характере течения данной патологии. На степень развития заболевания, очевидно, оказывают воздействие и другие факторы, такие как сопутствующая соматическая патология, факторы внешней среды, поведенческие стереотипы и др. Таким образом, можно рассматривать возникновение патологии пародонта как сложное взаимодействие бактериальной инфекции, метаболических нарушений, изменений в иммунном статусе, микроциркуляторном русле и ответной реакции организма [20].

Многочисленные современные исследования свидетельствуют о влиянии пародонтита на организм в целом и состояние здоровья пациента [21]. Доказано, что у пациентов с сопутствующими соматическими заболеваниями, такими, например, как сахарный диабет и артериальная гипертензия, вероятность развития и степень тяжести пародонтита существенно повышается [22; 23]. Поскольку взаимосвязь между степенью тяжести патологии пародонта и общими заболеваниями становится все более очевидной, происходит изменение подхода к профилактике и лечению заболеваний пародонта [24].

\section{Жировая ткань как основной орган, секретирующий провоспалительные цитокины}

Ожирение - одно из самых распространенных в мире хронических заболеваний. В настоящее время каждый четвертый житель нашей планеты уже имеет избыточную массу тела или страдает от ожирения. Во всех странах отмечается прогрессирующее увеличение численности больных с ожирением как среди взрослого, так и среди детского населения. Всемирная организация здравоохранения признала ожирение эпидемией XXI в. По прогнозам эпидемиологов, предполагается, что к 2025 г. от ожирения уже будут страдать $40 \%$ мужчин и $50 \%$ женщин [25].

С распространением ожирения по планете множатся и усугубляются связанные с ним тяжелые соматические заболевания - сахарный диабет 2-го типа, артериальная гипертензия, ишемическая болезнь сердца, онкологические заболевания и другие болезни, приводящие к ухудшению качества жизни, ранней потере трудоспособности и преждевременной смертности [26].

Несмотря на широкую распространенность, а также доказанную роль ожирения в патогенезе серьезных сопутствующих заболеваний, единая патогенетическая классификация ожирения к настоящему моменту не разработана. Предлагаются различные варианты классификаций ожирения, наиболее используемыми из которых являются классификация по индексу массы тела (ИМТ), рекомендованная 
ВОЗ, и рабочая этиопатогенетическая классификация ожирения (по И.И.Дедову и Г.А. Мельниченко) [27].

ИМТ является наиболее информативным показателем, который рассчитывается делением показателя массы тела в килограммах на показатель роста человека, выраженный в метрах и возведенный в квадрат $\left(к г / \mathrm{M}^{2}\right)$. Идеальное значение индекса составляет 18,5-24,9. Больший ИМТ ассоциирован с увеличением заболеваемости и смертности.

Жировая ткань является основным органом, секретирующим провоспалительные цитокины. Ожирение принято считать состоянием воспаления низкого уровня [28]. Существует тесная взаимосвязь между ожирением и воспалительной реакцией, она отражается в тесной взаимосвязи с концентрацией в плазме крови СРБ, который является маркером острой фазы системного воспаления [29; 30].

При анализе данных, полученных от обследования 16616 мужчин и женщин из NHANES III, обнаружена взаимосвязь между ожирением и уровнем СРБ, особенно у женщин [31]. После исключения сопутствующих факторов, влияющих на продукцию СРБ, была найдена корреляция между индексом массы тела и окружностью талии с уровнями СРБ в плазме крови. В дальнейшем японские исследователи подтвердили эти данные, а также обнаружили, что накопления висцерального жира сильнее коррелируют с СРБ, чем накопления в подкожно-жировой клетчатке [32].

Другим существенным фактором системного воспаления признан гормон лептин [33]. Согласно недавним исследованиям, лептин, первоначально известный своим воздействием на регулирование массы тела, метаболизм и функцию воспроизводства, также может быть частью некоторых воспалительных заболеваний, воздействуя на врожденный и приобретенный иммунный ответ [32]. Было показано, что продукт этого гена оказывает непосредственное влияние на количество жировой ткани [33]. При наличии лептина снижается аппетит и масса тела, а энергетические расходы, наоборот, растут [34; 35]. Во время поста и в голод уровень лептина в организме снижается, что вызывает рефлекторное увеличение аппетита [36]. Дефекты в экспрессии гена производства лептина или его рецепторов (генный диабет) могут стать причиной крайней степени ожирения [37]. Адипоциты ответственны за производство лептина, также эту функцию в незначительной мере выполняют клетки эпителия желудка и плацентарные клетки [38]. Недавно обнаружено, что клетки эпителия десны тоже производят лептин. В 2001 г. было проведено исследование на наличие лептина в тканях десны. Лептин обнаружен в здоровых и воспаленных деснах. Его количество уменьшалось в зависимости от степени воспаления и глубины его распространения. Был сделан вывод, что ткани десен являются еще одним источником лептина совместно с адипоцитами [39]. В ряде исследований было показано, что по мере увеличения воспалительного разрушения тканей пародонта концентрация лептина в десневой жидкости зубодесневой борозды увеличивается, а концентрация лептина в сыворотке крови имеет прямую корреляцию с хроническим пародонтитом [40].

В настоящее время нами проводится исследование, целью которого является оценка клинических особенностей, распространенности и взаимосвязи заболеваний пародонта и ожирения. Для достижения данной цели была проведена оценка состояния микроциркуляторного сосудистого русла тканей пародонта и костной ткани челюстных костей с использованием методов ультразвуковой допплеро- 
графии (аппарат Мениска Допплер-К) и ультразвуковой денситометрии (Sunlight Omniscence 7000). Будут проведены исследования липидного спектра и маркера воспаления - СРБ.

\section{Результаты исследований}

В нашем исследовании принимали участие 102 пациента с диагнозом «ожирение» и 51 пациент без ожирения (контрольная группа). Средний возраст обследуемых составил 57,4 9,3 лет у пациентов с ожирением и 54,0 $\pm 8,4$ лет у пациентов контрольной группы.

По итогам клинического и рентгенологического исследований больным из группы с ожирением и из контрольной группы были поставлены соответствующие диагнозы. Хронический генерализованный пародонтит (ХГП) тяжелой степени выявлен у 83 человек основной группы (81,4\%), средней степени - у 17 (16,7\%), легкой степени и пародонтоз - у 2 (по 0,9\%). У пациентов контрольной группы ХГП тяжелой степени был диагностирован только у 4 пациентов $(7,8 \%)$, средней степени - у 22 (43,1\%), легкой степени - у 18 (35,3\%), пародонтоз - у 7 (13,7\%).

Сравнивая степени тяжести патологии пародонта в основной и контрольной группах при помощи корреляционного анализа, получили достоверные различия между группами ( $<$ 0,0001) (рис. 1).

В результате корреляционного анализа была выявлена тесная взаимосвязь между степенью тяжести патологии пародиста и величиной ИМТ внутри групп. Для основной группы был получен коэффициент корреляции, равный 0,36; для

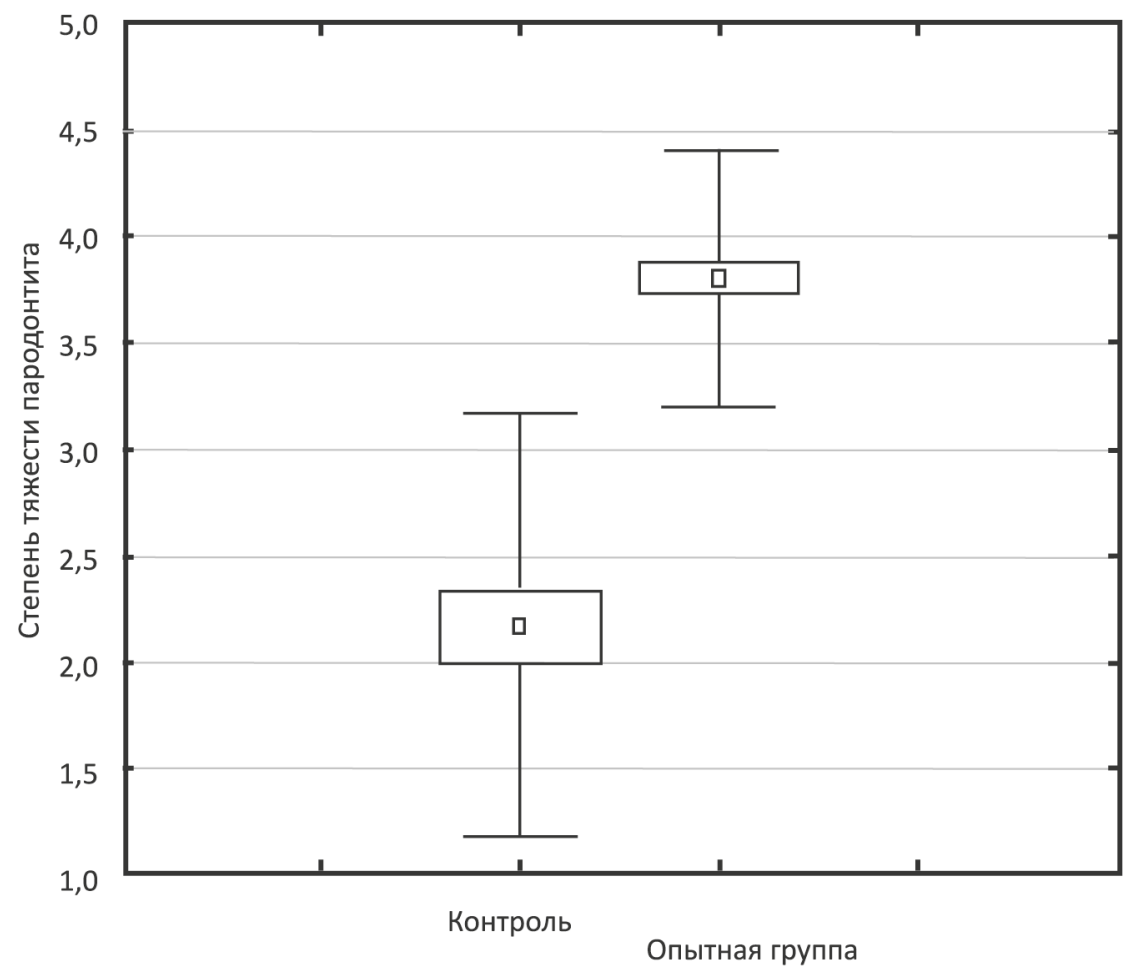

Puc. 1. Сравнение тяжести патологии пародонта по группам 
контрольной группы он составил 0,64, что подтверждает наличие прямой связи этих параметров с достоверностью $p=0,02$ (рис. 2).

$$
r=0,38016, p=0,002
$$

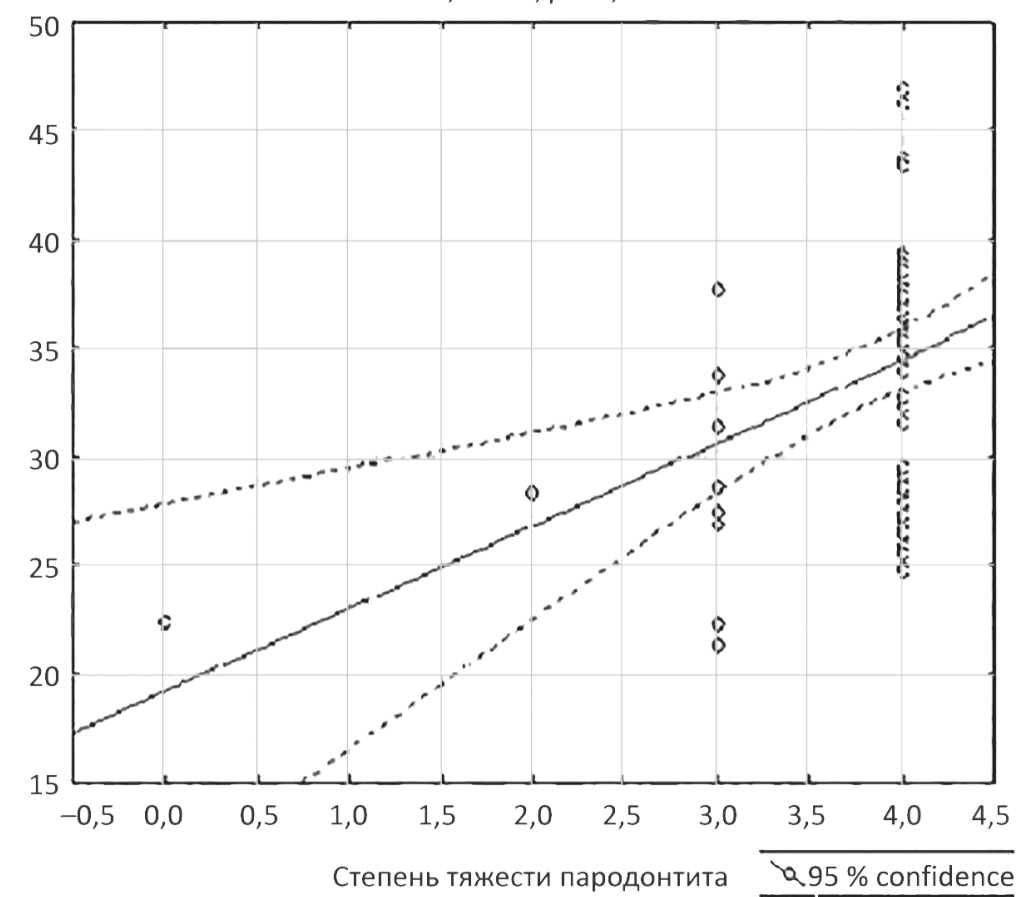

Puc. 2. Корреляция между тяжестью патологии пародонта и величиной ИМТ

Полученные в результате допплерографии сосудов пародонта данные показали обратную корреляционную связь между показателями индекса массы тела и линейной систолической скоростью кровотока $(r=-0,6754, p<0,001)$. Среднее значение показателя Vas для основной группы составило 0,364 $\pm 0,155$, а для контрольной группы - 0,644 0,146 . В ходе сравнения данных были получены достоверные различия между основной группой и группой контроля $(p<0,05)$.

Также при анализе результатов денситометрии была получена обратная корреляционная связь между показателями индекса массы тела и плотностью костной ткани $(r=-0,61, p<0,001)$. Среднее значение Т-индекса у пациентов основной группы составило $-2 \pm 0,77$, в группе контроля $-0,7 \pm 0,96$.

\section{Заключение}

Анализ литературных данных и полученные нами результаты исследования свидетельствуют о том, что существует этиопатогенетическая взаимосвязь между заболеваниями пародонта и ожирением. Понимание особенностей взаимовлияния этих двух заболеваний облегчит оценку прогноза у пациентов, страдающих этими заболеваниями, упростит выбор необходимой терапии с учетом влияния на микроциркуляцию и минеральную плотность костной ткани. Полученные результаты по- 
могут в разработке мер профилактики и своевременной диагностики поражения пародонта у пациентов с ожирением.

\section{Литература}

1. Артюшкевич А.С., Латьпиева С.В., Наумович С.А., Трофимова Е.К. Заболевания пародонта. М.: Медицинская литература, 2006. 328 с.

2. Ермолаева Л.А., Шишкин А.Н., Шевелева Н.А., Пеньковой Е. А., Шевелева М. А. Анализ взаимовлияния заболеваний пародонта и метаболического синдрома // Основные проблемы в современной медицине. Волгоград, 2015. № 2. С. 176-178.

3. Грудянов А. И., Григорян А. С., Фролова О. А. Диагностика в пародонтологии. М., 2004. 104 с.

4. Irani S., Schmidlin P., Bolivar I., Speich S., Boehler A. Evidence for graft colonization with periodontal pathogens in lung transplant recipients // Schweiz Monatsschr Zahnmed. 2011. N 12/201. P. 1144-1149.

5. Al-Hebshi N. N., Al-Sharabi A.K., Shuga-Aldin H.M., Al-Haroni M., Ghandour I. Effect of khat chewing on periodontal pathogens in subgingival biofilm from chronic periodontitis patients // J. Ethnopharmacol. 2010. N 132 (3). P. 564-569.

6. Hajishengallis G., Darveau R.P., Curtis M. A. The keystone-pathogen hypothesis // Nat. Rev. Microbiol. 2012. N 10 (10). P.717-725.

7. Belstrom D., Fiehn N.E., Nielsen C.H., Kirkby N., Twetman S., Klepac-Ceraj V., Paster B. J., Holmstrup $P$. Differences in bacterial saliva profile between periodontitis patients and a control cohort // J. Clin. Periodontol. 2014. N 41 (2). P. 104-112.

8. Sbordone L., Bortolaia C. Oral microbial biofilms and plaque-related diseases: microbial communities and their role in the shift from oral health to disease // Clinical Oral Investigations. 2003. N 7. P. 181-188.

9. Graves D. T., Fine D., Teng Y. T., Van Dyke T.E., Hajishengallis G. The use rodent models to investigate host-bacteria interactions related to periodontal diseases // J. Clin Periodontol. 2008. N 35. P. 89-105.

10. Микробиология и иммунология для стоматологов / под ред. Р.Дж.Ламонта, М.С.Лантц, Р. А. Берне, Д. Дж. Лебланка. М., 2010. 504 с.

11. Kinane D. F., Hart T. C. Genes and gene polymorphism associated with periodontal disease // Genes Crit. Rev. Oral Biol. Med. 2003. N 14. P. 430-449.

12. Hajishengallis G., Lamont R. J. Beyond the red complex and into more complexity: the polymicrobial synergy and dysbiosis (PSD) model of periodontal disease etiology // Mol. Oral Microbiol. 2012. N 27 (6). P. 409-419.

13. Yucel-Lindberg T., Bage T. Inflammatory mediators in the pathogenesis of periodontitis // Expert Reviews in Molecular Medicine. 2013. N 15. P.22.

14. Bansal T., Pandey A., Asthana A. K. C-Reactive Protein (CRP) and its Association with Periodontal Disease: A Brief Review // J. Cli. Diagn. Res. 2014. N 8 (7). P. 57-62.

15. Ramamoorthy R. D., Nallasamy V., Reddy R., Esther N. A review of C-reactive protein: A diagnostic indicator in periodontal medicine // J. Pharm Bioallied Sci. 2012. N 4 (Suppl. 2). P. 238-245.

16. Yoshi S., Tsuboi S., Morita I., Takami Y., Adachi K., Inukai J., Inagaki K., Mizuno K., Nakagaki H. Temporal association of elevated C-reactive protein and periodontal disease in men // J. Periodontol. 2013. Vol. 80 (5). P. 734-739.

17. Vidal F., Figueredo C.M., Cordovil I., Fischer R. G. Periodontal therapy reduces plasma levels of interleukin-6, C-reactive protein, and fibrinogen in patients with severe periodontitis and refractory arterial hypertension // J. Periodontol. 2009. Vol. 80 (5). P.786-791.

18. Kaustubh T., Vikas D., Manohar B. Evaluation of C-reactive protein serum levels in periodontitis patients with or without atherosclerosis // Indian Journal of Dental Research. 2010. N 21. P.326-329.

19. Deschner J., Nokhbehsaim M. Regulatory effects of inflammatory and biomechanical signals on regenerative periodontal healing // International Journal of Oral \& Maxillofacial Implants. 2013. N 28. P. 472-477.

20. Ермолаева Л.А., Шишкин А.Н., Шевелева Н.А., Шевелева М.А., Пеньковой Е.А. Ожирение и заболевания пародонта // International scientific and practical conference world science. Dubai, 2015. Vol.2, N 3 (3). P. 54-56.

21. Elter J.R., Catherine M.E., Offenbacher S., Beck J.D. Relationship of periodontal disease and tooth loss to prevalence of coronary heart disease // J.Periodontol. 2004. Vol.75 (6). P.782-790.

22. Marchetti E., Monaco A., Procaccini L., Mummolo S., Gatto R., Tetè S., Baldini A., Tecco S., Marzo G. Periodontal disease: the influence of metabolic syndrome // Nutrition \& Metabolism. 2012. Vol. 9 (1). P. 88.

23. Osazuwa F., Onoriode M.A., Adeolu A.A. Markers of inflammation among Nigerian periodontitis patients // Journal of Immunological Techniques in Infectious Diseases. 2014. Vol. 3 (2). P. 32. 
24. Preshaw P. M., Alba A. L., Herrera D., Jepsen S., Konstantinidis A., Makrilakis K., Taylor R. Periodontitis and diabetes: a two-way relationship // Diabetologia. 2012. Vol. 55 (1). P. 31.

25. Nguyen D.M., El-Serag H.B. The epidemiology of obesity // Gastroenterology Clinics of North America. 2010. N 39. P. 1-7.

26. Singer R. E., Moss K., Kim S. J., Beck J.D., Offenbacher S. Oxidative stress and IgG antibody modify periodontitis-CRP Association // J. Dent. Res. 2015. Vol. 94 (12). P. 1698-1670.

27. Дедов И. И., Мельниченко Г.А. Ожирение. Этиология, патогенез, клинические аспекты // Руководство для врачей. М., 2004.

28. Toprak D., Toprak A., Chen W., Xu J.H., Srinivasan S., Berenson S. Adiposity in childhood is related to C-reactive protein and adiponectin in young adulthood: from the Bogalusa Heart Study // Obesity. 2011. Vol. 19, issue 1. P. 185-190.

29. Jeemon P., Prabhakaran D., Ramakrishnan L., Ahmed F., Thankappan K., Kartha C., Chaturvedi V., Reddy K. Association of high sensitive C-reactive protein (hsCRP) with established cardiovascular risk factors in the Indian population // Nutr. Metab. 2011. Vol. 8 (1). P. 19-27.

30. Faucher G., Guénard F., Bouchard L., Garneau V., Turcot V., Houde A., Tchernof A., Bergeron J., Deshaies Y., Hould F. S., Lebel S., Marceau P., Vohl M. C. Genetic contribution to C-reactive protein levels in severe obesity // Mol. Genet Metab. 2012. Vol. 105 (3). P. 494-501.

31. Weatherall D. J., Ledingham J.G., Warrell D. A. The acute phase response and C-reactive protein // Oxford textbook of Medicine. Edition $3^{\text {rd }}$. New York; Oxford, 1996. P. 1527-1533.

32. Saito T., Murakami M., Shimazaki Y., Oobayashi K., Matsumoto S., Koga T. Association between alveolar bone loss and elevated serum C-reactive protein in Japanese men // J. Periodontol. 2003. Vol. 74 (12). P. 1741-1746.

33. Ay Z. Y., Kirziogg F. Y., Tonguc M. O., Su R., Kapucuoglu N. The gingiva contains leptin and leptin receptor in health and disease // Odontology. 2012. N 100. P.222-231.

34. Li W., Zhu W., Hou J., Huang B., Liu K., Meng H. Leptin and its receptor expression in dental and periodontal tissues of primates // Cell and Tissue Research. 2014. N 355. P. 181-188.

35. Romanos G. E., Asnani K. P., Hingorani D., Desh-mukh V.L. PERIOSTIN: role in formation and maintenance of dental tissues // Journal of Cellular Physiology. 2014. N 229. P. 1-5.

36. Jeemon P., Prabhakaran D., Ramakrishnan L., Gupta R., Ahmed F., Thankappan K. P., Kartha C.C., Chaturvedi V., Reddy K. S. Association of high sensitive C-reactive protein (hsCRP) with established cardiovascular risk factors in the Indian population // Nutr. Metab. 2011. Vol. 8 (19). P. 19-27.

37. Faucher G., Guénard F., Bouchard L., Garneau V., Turcot V., Houde A., Tchernof A., Bergeron J., Deshaies Y., Hould F. S., Lebel S., Marceau P., Vohl M. C. Genetic contribution to C-reactive protein levels in severe obesity // Mol. Genet. Metab. 2012. Vol. 105 (3). P. 494-501.

38. Procaccini C., Jirillo E., Matarese G. Leptin as an immunomodulator // Molecular Aspects of Medicine. 2012. N 33. P. 35-45.

39. Johnson R. B., Serio F. G. Leptin within healthy and diseased human gingiva // J. Periodontol. 2001. N 72. P. 1254-1257.

40. Karthikeyan B. V., Pradeep A. R. Leptin levels in gingival crevicular fluid in periodontal health and disease // Journal of Periodontal Research. 2007. Vol. 42. N 4. P.300-304.

Для цитирования: Ермолаева Л.А., Севбитов А. В., Пеньковой Е.А., Шиикин А.Н., Шевелева Н.А., Шевелева М. А., Соколович Н. А., Михайлова Е. С., Хабарова О. В. Этиопатогенетические механизмы развития воспалительных заболеваний пародонта у больных с ожирением // Вестник СПбГУ. Медицина. 2017. Т. 12. Вып. 4. С. 385-395. https://doi.org/10.21638/11701/spbu11.2017.407

\section{References}

1. Artiushkevich A.S., Latysheva S. V., Naumovich S. A., Trofimova E.K. Zabolevaniia parodonta [Periodontal diseases]. Moscow, Meditsinskaia Literature Publ., 2006. 328 p. (In Russian)

2. Ermolaeva L. A., Shishkin A. N., Sheveleva N. A., Pen’kovoi E. A., Sheveleva M. A. Analiz vzaimovliianiia zabolevanii parodonta i metabolicheskogo sindroma [Analysis of the interaction of periodontal disease and metabolic syndrome]. Osnovnye problemy v sovremennoi meditsine [The main problems in modern medicine]. Volgograd, 2015, no. 2, pp. 176-178. (In Russian)

3. Grudianov A.I., Grigorian A.S., Frolova O.A. Diagnostika $v$ parodontologii [Diagnostics in periodontology]. Moscow, 2004. 104 p. (In Russian)

4. Irani S., Schmidlin P., Bolivar I., Speich S., Boehler A. Evidence for graft colonization with periodontal pathogens in lung transplant recipients. Schweiz Monatsschr Zahnmed, 2011, no. 12/201, pp. 1144-1149. 
5. Al-Hebshi N.N., Al-Sharabi A.K., Shuga-Aldin H.M., Al-Haroni M., Ghandour I. Effect of khat chewing on periodontal pathogens in subgingival biofilm from chronic periodontitis patients. J. Ethnopharmacol., 2010, no. 132 (3), pp. 564-569.

6. Hajishengallis G., Darveau R. P., Curtis M. A. The keystone-pathogen hypothesis. Nat. Rev. Microbiol., 2012, no. 10 (10), pp. 717-725.

7. Belstrom D., Fiehn N.E., Nielsen C.H., Kirkby N., Twetman S., Klepac-Ceraj V., Paster B.J., Holmstrup P. Differences in bacterial saliva profile between periodontitis patients and a control cohort. J. Clin. Periodontol., 2014, no. 41 (2), pp. 104-112.

8. Sbordone L., Bortolaia C. Oral microbial biofilms and plaque-related diseases: microbial communities and their role in the shift from oral health to disease. Clinical Oral Investigations, 2003, no. 7, pp. 181-188.

9. Graves D. T., Fine D., Teng Y. T., Van Dyke T.E., Hajishengallis G. The use rodent models to investigate host-bacteria interactions related to periodontal diseases. J. Clin Periodontol., 2008, no. 35, pp. 89-105.

10. Oral microbiology and immunology. Eds R.J.Lamont, R.A.Burne, M.S.Lantz, D. J.LeBlanc. Washington, 2006. (Russ. ed.: Mikrobiologiia i immunologiia dlia stomatologoviu. Eds R.Dzh. Lamont, M. S. Lantts, R. A. Berne, D. Dzh. Leblank. Moscow, 2010. 504 p.).

11. Kinane D.F., Hart T.C. Genes and gene polymorphism associated with periodontal disease. Genes Crit. Rev. Oral Biol. Med., 2003, no. 14, pp. 430-449.

12. Hajishengallis G., Lamont R. J. Beyond the red complex and into more complexity: the polymicrobial synergy and dysbiosis (PSD) model of periodontal disease etiology. Mol. Oral Microbiol., 2012, no. 27 (6), pp. 409-419.

13. Yucel-Lindberg T., Bage T. Inflammatory mediators in the pathogenesis of periodontitis. Expert Reviews in Molecular Medicine, 2013, no. 15, p. 22.

14. Bansal T., Pandey A., Asthana A. K. C-Reactive Protein (CRP) and its Association with Periodontal Disease: A Brief Review. J. Cli. Diagn. Res., 2014, no. 8 (7), pp. 57-62.

15. Ramamoorthy R. D., Nallasamy V., Reddy R., Esther N. A review of C-reactive protein: A diagnostic indicator in periodontal medicine. J. Pharm Bioallied Sci., 2012, no. 4 (Suppl. 2), pp. 238-245.

16. Yoshi S., Tsuboi S., Morita I., Takami Y., Adachi K., Inukai J., Inagaki K., Mizuno K., Nakagaki H. Temporal association of elevated C-reactive protein and periodontal disease in men. J.Periodontol., 2013, vol. 80 (5), pp. 734-739.

17. Vidal F., Figueredo C.M., Cordovil I., Fischer R.G. Periodontal therapy reduces plasma levels of interleukin-6, C-reactive protein, and fibrinogen in patients with severe periodontitis and refractory arterial hypertension. J. Periodontol., 2009, vol. 80 (5), pp. 786-791.

18. Kaustubh T., Vikas D., Manohar B. Evaluation of C-reactive protein serum levels in periodontitis patients with or without atherosclerosis. Indian Journal of Dental Research, 2010, no. 21, pp. 326-329.

19. Deschner J., Nokhbehsaim M. Regulatory effects of inflammatory and biomechanical signals on regenerative periodontal healing. International Journal of Oral \& Maxillofacial Implants, 2013, no. 28, pp. $472-477$.

20. Ermolaeva L.A., Shishkin A.N., Sheveleva N.A., Sheveleva M.A., Pen'kovoi E.A. Ozhirenie i zabolevaniia parodonta [Obesity and periodontal disease]. International scientific and practical conference world science. Dubai, 2015, vol. 2, no. 3 (3), pp. 54-56. (In Russian)

21. Elter J.R., Catherine M.E., Offenbacher S., Beck J.D. Relationship of periodontal disease and tooth loss to prevalence of coronary heart disease. J.Periodontol., 2004, vol. 75 (6), pp. 782-790.

22. Marchetti E., Monaco A., Procaccini L., Mummolo S., Gatto R., Tetè S., Baldini A., Tecco S., Marzo G. Periodontal disease: the influence of metabolic syndrome. Nutrition \& Metabolism, 2012, vol. 9 (1), p. 88.

23. Osazuwa F., Onoriode M. A., Adeolu A. A. Markers of inflammation among Nigerian periodontitis patients. Journal of Immunological Techniques in Infectious Diseases, 2014, vol. 3 (2), p. 32.

24. Preshaw P.M., Alba A.L., Herrera D., Jepsen S., Konstantinidis A., Makrilakis K., Taylor R. Periodontitis and diabetes: a two-way relationship. Diabetologia, 2012, vol. 55 (1), p. 31.

25. Nguyen D. M., El-Serag H. B. The epidemiology of obesity. Gastroenterology Clinics of North America, 2010, no. 39, pp. $1-7$.

26. Singer R.E., Moss K., Kim S. J., Beck J. D., Offenbacher S. Oxidative stress and IgG antibody modify periodontitis-CRP Association. J. Dent. Res., 2015, vol. 94 (12), pp. 1698-1670.

27. Dedov I.I., Mel'nichenko G. A. Ozhirenie. Etiologiia, patogenez, klinicheskie aspekty [Obesity. Etiology, pathogenesis, clinical aspects]. Rukovodstvo dlia vrachei [A guide for doctors]. Moscow, 2004. (In Russian)

28. Toprak D., Toprak A., Chen W., Xu J.H., Srinivasan S., Berenson S. Adiposity in childhood is related to C-reactive protein and adiponectin in young adulthood: from the Bogalusa Heart Study. Obesity, 2011, vol. 19, issue 1, pp. 185-190. 
29. Jeemon P., Prabhakaran D., Ramakrishnan L., Ahmed F., Thankappan K., Kartha C., Chaturvedi V., Reddy K. Association of high sensitive C-reactive protein (hsCRP) with established cardiovascular risk factors in the Indian population. Nutr. Metab., 2011, vol. 8 (1), pp. 19-27.

30. Faucher G., Guénard F., Bouchard L., Garneau V., Turcot V., Houde A., Tchernof A., Bergeron J., Deshaies Y., Hould F. S., Lebel S., Marceau P., Vohl M. C. Genetic contribution to C-reactive protein levels in severe obesity. Mol. Genet Metab., 2012, vol. 105 (3), pp. 494-501.

31. Weatherall D. J., Ledingham J.G., Warrell D. A. The acute phase response and C-reactive protein. Oxford textbook of Medicine. Edition $3^{\text {rd }}$. N. Y., Oxford, 1996, pp. 1527-1533.

32. Saito T., Murakami M., Shimazaki Y., Oobayashi K., Matsumoto S., Koga T. Association between alveolar bone loss and elevated serum C-reactive protein in Japanese men. J.Periodontol., 2003, vol. 74 (12), pp. 1741-1746.

33. Ay Z. Y., Kirziogg F. Y., Tonguc M. O., Su R., Kapucuoglu N. The gingiva contains leptin and leptin receptor in health and disease. Odontology, 2012, no. 100, pp. 222-231.

34. Li W., Zhu W., Hou J., Huang B., Liu K., Meng H. Leptin and its receptor expression in dental and periodontal tissues of primates. Cell and Tissue Research, 2014, no. 355, pp. 181-188.

35. Romanos G.E., Asnani K. P., Hingorani D., Desh-mukh V.L. PERIOSTIN: role in formation and maintenance of dental tissues. Journal of Cellular Physiology, 2014, no. 229, pp. 1-5.

36. Jeemon P., Prabhakaran D., Ramakrishnan L., Gupta R., Ahmed F., Thankappan K. P., Kartha C. C., Chaturvedi V., Reddy K.S. Association of high sensitive C-reactive protein (hsCRP) with established cardiovascular risk factors in the Indian population. Nutr. Metab., 2011, vol. 8 (19), pp. 19-27.

37. Faucher G., Guénard F., Bouchard L., Garneau V., Turcot V., Houde A., Tchernof A., Bergeron J., Deshaies Y., Hould F. S., Lebel S., Marceau P., Vohl M. C. Genetic contribution to C-reactive protein levels in severe obesity. Mol. Genet. Metab., 2012, vol. 105 (3), pp. 494-501.

38. Procaccini C., Jirillo E., Matarese G. Leptin as an immunomodulator. Molecular Aspects of Medicine, 2012, no. 33, pp. 35-45.

39. Johnson R. B., Serio F. G. Leptin within healthy and diseased human gingiva. J.Periodontol., 2001, no. 72 , pp. $1254-1257$.

40. Karthikeyan B. V., Pradeep A. R. Leptin levels in gingival crevicular fluid in periodontal health and disease. Journal of Periodontal Research, 2007, vol. 42, no. 4, pp. 300-304.

For citation: Ermolaeva L.A., Sevbitov A.V., Penkovoi E.A., Shishkin A.N., Sheveleva N.A., Sheveleva M.A., Sokolovich N.A., Mikhaylova E.S., Khabarova O. V. Etiopathogenetic mechanisms of development of inflammatory periodontal diseases in patients with obesity. Vestnik SPbSU. Medicine, 2017, vol. 12, issue 4, pp.385-395. https://doi.org/10.21638/11701/spbu11.2017.407

Статья поступила в редакцию 28 ноября 2016 г. Статья принята в печать 11 сентября 2017 г.

Контактная информация:

Ермолаева Людмила Александровна - доктор медицинских наук, доцент; e9573821@yandex.ru Севбитов Андрей Владимирович - доктор медицинских наук, профессор; avsevbitov@mail.ru Пеньковой Евгений Александрович - аспирант; pin116@mail.ru

Шишкин Александр Николаевич - доктор медицинских наук, профессор, alexshishkin@bk.ru Шевелева Наталья Александровна - кандидат медицинских наук; bijou_86@mail.ru Шевелева Марина Анатольевна - кандидат медицинских наук, доцент; msheveleva@list.ru Соколович Наталия Александровна - доктор медицинских наук, профессор; lun_nat@mail.ru Михайлова Екатерина Станиславовна - кандидат медицинских наук; catpara72@mail.ru Хабарова Ольга Витальевна - х9045000@yandex.ru

Ermolaeva Lyudmila A. - MD, Professor; e9573821@yandex.ru

Sevbitov Andrey V. - MD, Professor; avsevbitov@mail.ru

Penkovoi Evgeny A. - Postgraduate; in116@mail.ru

Shishkin Alexander N. - MD, Professor; alexshishkin@bk.ru

Sheveleva Natalia A. — PhD; bijou_86@mail.ru

Sheveleva Marina A. — PhD; msheveleva@list.ru

Sokolovich Natalia A. - MD, Professor; lun_nat@mail.ru

Mikhaylova Ekaterina S. _- PhD; catpara72@mail.ru

Khabarova Olga V. - x9045000@yandex.ru 